\title{
Atmosphere and ocean dynamics: contributors to the European Little Ice Age?
}

\author{
V. Palastanga $\cdot$ G. van der Schrier $\cdot$ S. L. Weber $\cdot$ \\ T. Kleinen · K. R. Briffa • T. J. Osborn
}

Received: 13 July 2009/Accepted: 21 January 2010/Published online: 16 February 2010

(C) The Author(s) 2010. This article is published with open access at Springerlink.com

\begin{abstract}
The role of a reduction in the Atlantic meridional overturning and that of a persistently negative North Atlantic Oscillation in explaining the coldness of the European Little Ice Age (LIA) has been assessed in two sets of numerical experiments. These experiments are performed using an intermediate complexity climate model and a full complexity GCM. The reduction in the Meridional Overturning Circulation (MOC) of ca. 25\% is triggered by a conventional fresh-water hosing set-up. A persistently negative NAO winter circulation, at NAOindex value -0.5 , is imposed using recently developed data-assimilation techniques applicable on paleoclimatic timescales. The hosing experiments lead to a reduction in oceanic meridional heat transport and cooler sea-surface temperatures. Next to a direct cooling effect on European climate, the change in ocean surface temperatures feedback on the atmospheric circulation modifying European climate significantly. The data-assimilation experiments showed a reduction of winter temperatures over parts of Europe, but there is little persistence into the summer season. The output of all model experiments are compared to reconstructions of winter and summer temperature based on the available temperature data for the LIA period. This
\end{abstract}

V. Palastanga $\cdot$ G. van der Schrier $(\bowtie) \cdot$ S. L. Weber

Royal Netherlands Meteorological Institute (KNMI),

P.O. Box 201, 3730 AE De Bilt, The Netherlands

e-mail: schrier@knmi.nl

T. Kleinen · K. R. Briffa · T. J. Osborn

Climatic Research Unit, School of Environmental Sciences,

University of East Anglia, Norwich NR4 7TJ, UK

Present Address:

T. Kleinen

Max Planck Institute for Meteorology, Hamburg, Germany demonstrates that the hypothesis of a persistently negative $\mathrm{NAO}$ as an explanation for the European LIA does not hold. The hosing experiments do not clearly support the hypothesis that a reduction in the MOC is the primary driver of LIA climate change. However, a reduction in the Atlantic overturning might have been a cause of the European LIA climate, depending on whether there is a strong enough feedback on the atmospheric circulation.

Keywords Little Ice Age .

Meridional Overturning Circulation .

North Atlantic Oscillation · Data assimilation

\section{Introduction}

Recent reconstructions of European temperatures provide some context and allow an assessment of the amplitude of the natural climate changes that affected the continent over the last 500 years (Luterbacher et al. 2004). In particular, European climate between the 16th and 19th centuries has seen cold multi-decadal periods, within the period known as the "Little Ice Age" (LIA) (Bradley and Jones 1993). While changes in solar variability and volcanism are possibly main causes for the global cooling of the LIA (Jansen et al. 2007), feedbacks via atmospheric and ocean dynamics determine the regional climate response to a large extent. Over the North Atlantic sector, changes in the atmospheric circulation patterns (Luterbacher et al. 2001, 2002), sea surface temperatures (Keigwin 1996; Keigwin and Pickart 1999) and sea ice cover (Ogilvie and Jonsson 2001) were documented during the LIA, and links between the modes of variability of the atmospheric circulation and the LIA period were proposed (Luterbacher et al. 2002; Shindell et al. 2001). It has also been speculated whether 
changes in the ocean thermohaline circulation were responsible for the LIA coldness (Bianchi and McCave 1999; Broecker 2000). Still, the relative importance of these mechanisms in shaping the regional and global characteristics of the LIA climate needs to be clarified.

The North Atlantic Oscillation (NAO) is the main mode of winter atmospheric circulation variability in the North Atlantic (Hurrel 1995), and is coupled to the North Atlantic sea surface temperature (SST) through latent heat fluxes (Rodwell et al. 1999). The state of the NAO, measured as the difference in sea level pressure (SLP) between the Azores and Iceland, relates to the strength of the westerly circulation that carries warm and wet air from the Atlantic into western Europe. Reconstructions of the SLP fields back to 1,500 indicate that the negative phase of the NAO has been more active during extreme cold periods of the LIA, leading to reduced influence of the moist and warm zonal flow from the northeastern North Atlantic, which favored cool and dry European winters (Luterbacher et al. 2001, 2002). In addition, the recurrence of positive SLP anomalies centered over Scandinavia or northern Europe, which caused anomalous advection of cold air towards central and eastern Europe, enhanced the wintertime cooling (Luterbacher et al. 2001). Several reconstructions of the NAO index from independent proxy data (Rodrigo et al. 2001; Cook et al. 2002) support a link between the negative phase of the NAO and long lasting cold periods within the LIA. This hypothesis was substantiated by the modeling study of Shindell et al. (2001), who showed a relationship between external forcings (i.e. reduced irradiance) and the NAO. Basically, changes in the stratospheric temperature and wind anomalies modify the mid-latitude planetary waves refraction, which interact with the intensity of the westerly winds, and subsequent the NAO. The experiment confirmed that regional climate changes associated with the changing state of the NAO can be much stronger than hemisphere wide changes.

Recently, the opposite with a persistently positive phase of the winter NAO leading to warm climatic spells has been identified to have occurred in the Medieval Climate Anomaly (Trouet et al. 2009).

Variations in the meridional heat transported by the Meridional Overturning Circulation (MOC) in the North Atlantic affect the heat loss to the atmosphere at mid and high latitudes, and consequently influence the climate downstream. Although one study hypothesized that a slowdown of the MOC may have acted as an amplifying mechanism in the LIA (Bond et al. 1997), to date, the evidence for Holocene MOC variability from geochemical proxy data is inconclusive (Keigwin and Boyle 2000). Bianchi and McCave (1999) analyzed from sediment grain size the speed of the Iceland-Scotland overflow water (ISOW), one of the components of North Atlantic deep water, and found that since 8,000 years ago cold climate periods, including the LIA, coincided with a less intense overflow, and vice versa. On interdecadal time scales, the rate of deep water formation in the North Atlantic has been linked to the NAO (Dickson et al. 1996). The strong NAO minimum of the early 1960s lead to a reduction and ultimately a cessation of deep water formation in the Labrador Seas, while formation of deep water in the Greenland Sea reach a maximum in that period. Recently, observations by Boessenkool et al. (2007) showed an inverse correlation between the ISOW and the NAO, and suggest that interdecadal changes in Labrador Sea water play a key role in transmitting the NAO signal to the deep ocean overflows.

The present study aims to distinguish between a persistently negative NAO-type circulation and a reduction in the Atlantic MOC as the primary drivers of the cooling observed in the European LIA. Two types of experiments are conducted; one in which a climate is simulated with a constant and negative NAO-index in winter, and one with a reduced overturning. In order to distinguish between the two hypothesis for LIA climate change, we need to compare the model results with a reconstruction of LIA climate. We only compare simulated and reconstructed temperatures; other elements, like precipitation, are not included in this comparison. The temperature reconstruction used is from Luterbacher et al. (2004) and is based on a mixture of proxy-records and early instrumental temperatures. The experiments conducted in this study should be regarded as sensitivity experiments in an idealized framework. Nevertheless, the comparison between the experiments and reconstructed climate will shed some light on the question which process is more likely to have occurred and is more likely to contribute to the coldness of the European LIA. Moreover, the comparison with a reconstruction of climate may also result in the conclusion that neither hypothesis seems likely to be valid, indicating that the drivers for LIA climate change are more complex than suggested by the two simple hypotheses investigated in this study.

In the present study we use a General Circulation Model (GCM) of intermediate complexity and a state-of-the-art GCM to investigate the separate effects of a reduced MOC and of a persistently negative NAO phase on setting the anomalous coldness of the LIA. The difference in model complexity should give an estimate of the robustness of the results.

For the first experiment, a freshwater flux is added to the North Atlantic Ocean to force a reduction of the MOC. For the second experiment, we impose a negative NAO-type circulation representative of the LIA period (Luterbacher et al. 2002) on the model atmosphere. For this purpose, two data assimilation techniques are used that reproduce, in a time averaged sense, the prescribed perturbation in the 
large-scale atmospheric circulation. Both techniques leave the atmosphere free to respond in a dynamically consistent way to the change in climatic conditions; in particular, synoptic scale variability is not suppressed.

All experiments conducted in this study are idealized to the point that radiation changes, due to changes in dust loading related to explosive volcanic outbursts or changes in solar activity, are ignored. Changes in the radiation balance must have been important for explaining LIA climate (e.g. Grove 1988), and in that sense the experimental set-up is an oversimplification. However, the direct effects of changes in the radiation budget will lead to large-scale changes in climate. In this study we are interested in the patterns of LIA climate change over Europe. An additional motivation for this idealized setting is that combining more than one possible driver of LIA climate change in the experiments will complicate the interpretation of the results.

Recently, Sedlácek and Mysak (2009) attempted to model the response of the North Atlantic ocean in the LIA period. They prescribed constant windstress field associated with negative NAO type circulations in their intermediate complexity GCM. Their experiment has some similarities to the data-assimilation experiments performed in this study in that the impact of the anomalous character of the LIA atmospheric circulation on the ocean circulation is estimated. However, an advantage of the approach adopted in the current study is that the ocean-atmospheresea ice system remains coupled in a dynamically consistent way, while synoptic variability is maintained.

The paper is organized as follows. Section 2 briefly describes the models and experimental design. Section 3 includes a short summary of the data assimilation techniques used to force the NAO towards a long term negative value. Section 4 presents the results of the freshwater hosing and negative NAO-assimilated pattern experiment. Finally, Sect. 5 contains a discussion and conclusions.

\section{Model description and experiment design}

\subsection{ECBilt-Clio Model description}

The intermediate complexity model, ECBilt-Clio, is a coupled ocean-atmosphere-sea ice general circulation model (Opsteegh et al. 1998; Goosse and Fichefet 1999). The atmospheric component (ECBilt) resolves 21 wavelengths around the globe, and it has 3 levels in the vertical, at 800,500 and $200 \mathrm{hPa}$. The dynamical part is an extended quasi-geostrophic model where the neglected ageostrophic terms are included in the vorticity and thermodynamic equations as a time dependent and spatially varying forcing. With this forcing the model simulates the Hadley circulation qualitatively correctly, and the strength and position of the jet stream and transient eddy activity become fairly realistic in comparison to other T21 models. The essentials of baroclinic instability are included, but the variability associated with it is underestimated compared to modern observations. The model contains simple physical parameterizations, including a full hydrological cycle.

The oceanic component (Clio) is a primitive equation, free-surface ocean general circulation model coupled to a thermodynamic-dynamic sea ice model and includes a relatively sophisticated parametrization of vertical mixing (Goosse et al. 1999). A three-layer sea-ice model, which takes into account sensible and latent heat storage in the snow-ice system, simulates the changes of snow and ice thickness in response to surface and bottom heat fluxes. The horizontal resolution of Clio is $3^{\circ} \times 3^{\circ}$ and it has 20 unevenly spaced layers in the vertical.

\subsection{HadCM3 Model description}

HadCM3 is the third version of the Hadley Centre coupled Atmosphere-Ocean GCM and has been described in detail by Pope et al. (2000) and Gordon et al. (2000), where a validation of some climate parameters is also given. Here, only a brief description of the model is given. The atmospheric part of HadCM3 employs a longitude-latitude grid with a resolution of $3.75^{\circ}$ by $2.5^{\circ}$. Vertically, the model resolves 19 layers in a hybrid coordinate system. The ocean component has a higher resolution of $1.25^{\circ}$ by $1.25^{\circ}$ on 19 unevenly spaced levels with increasing resolution near the ocean surface. HadCM3 produces a stable climate without the use of flux adjustments, with the exception of the deep ocean, where a small drift remains (Pardaens et al. 2003). The sea ice model uses a simple thermodynamic scheme and contains parameterizations of ice drifts.

\subsection{Experiments}

In the first of the two sets of experiments performed with the ECBilt-Clio and HadCM3 models, a negative state of the NAO is imposed on the model's atmosphere by forcing the NAO index towards a 30 year-mean value of approximately -0.5 . For the ECBilt-Clio model, we use a data assimilation technique developed at the European Centre for Medium Range Weather Forecasts (ECMWF), which applies an adjoint model. This method has been successfully applied in recent paleoclimatology studies with the ECBilt-Clio model (van der Schrier and Barkmeijer 2005, 2007; van der Schrier et al. 2007). As it is not feasible to construct an adjoint model for a GCM as 
HadCM3, here we use an assimilation algorithm based on the Data Assimilation through Upscaling and Nudging (DATUN) or "pattern nudging" method (von Storch et al. 2000; Jones and Widmann 2003). A description of both data assimilation approaches and their differences is given in the Appendix.

Both data assimilation techniques assimilate large-scale changes in the atmospheric circulation by calculating an artificial forcing to the model tendencies. The method of calculating this additional forcing, as well as the actual forcing fields, differ between the two models. Both assimilation methods are designed specifically to modify the large-scale circulation without suppressing the synoptic scale variability, which can adjust in a dynamically consistent way.

In this experiment, we only assimilate a negative NAO-like circulation in the model and do not change irradiance, parameterizing solar activity or changes in atmospheric dust loading due to explosive volcanic eruptions. No action is taken to change the strength of the MOC either.

The second experiment consists of a freshwater hosing in order to reduce the mean strength of the MOC by about $25 \%$. To achieve this, an artificial freshwater flux of $0.1 \mathrm{~Sv}$ in the HadCM3 model and of $0.075 \mathrm{~Sv}$ in the ECBilt-Clio model is added to the North Atlantic basin between $50^{\circ} \mathrm{N}$ and $70^{\circ} \mathrm{N}$ in a similar way to that described by Stouffer et al. (2006). The induced reduction in the overturning depends on both the magnitude and duration of the perturbation. The aim of the latter experiment is not to simulate a complete shut down of the MOC, as even for the extreme climate of the Last Glacial Maximum proxy data indicated a MOC reduction of no more than $30 \%$ compared to present climate (Weber et al. 2007). A decrease of that latter magnitude would be consistent with available Holocene paleoclimatic data (Bianchi and McCave 1999). A reduction of the intensity of the MOC by $25 \%$ for a simulation of LIA climate is then at the upper range of what could be considered as compatible with data. In the HadCM3 model, the freshwater pulse is implemented from year 100 onwards of the control run and is held constant during 100 years of integration, while for the ECBilt-Clio model we consider a simulation of 300 years, in which the perturbation is applied from year 50 onwards and is held constant over 50 years. For the ECBilt-Clio model, we analyze a 100year period right after the cessation of the freswater inflow. The strength of the overturning remains (statistically) constant over this period. The inflow of freshwater is constant in time and a possible simulation of Heinrich events is not attempted. In this experiment, we only modify the strength of the MOC and do not assimilate a negative NAO-like circulation or change the irradiance in an effort to accommodate changes in solar activity or changes in atmospheric dust loading.

An effective way of modifying the mean strength of the MOC is by addition of freshwater to the model ocean. With this experiment, we do not claim that if a MOC change may have been instrumental for Europe's cold climate during the LIA, that an increase in freshwater inflow must have occurred. The scope of this study does not include an analysis of the causes for a possible reduction in MOC during Europe's LIA, nor for the causes of a persistently negative NAO-like circulation for that matter.

In addition to the above simulations, a 200 year control run at preindustrial conditions with HadCM3, which is itself a continuation of an earlier control run performed at the Hadley Centre, and a 100 years control run with the ECBilt-Clio model are performed.

\subsection{Nudging method}

Nudging was originally developed as a method for the assimilation of measurement data into weather forecasting models. The general idea in nudging is that the distance between the model state and the measurements of meteorological variables is minimized at every grid point of the weather forecasting model by adding correction terms to the model fields.

In contrast to conventional nudging approaches, the pattern nudging in the DATUN method is based on a decomposition of the model field into a climatology and a set of orthogonal modes as in Eq. (1) of the Appendix. The model dynamics are forced towards the large scale target pattern, without directly affecting components of the climate state that are not constrained by proxy data, and without suppressing synoptic-scale variability. A more expansive discussion on the approach can be found in Jones and Widmann (2003) and Widmann et al. (2009). The implementation of this technique in HadCM3 can be found in Kleinen et al. (2007). See Widmann et al. (2009) for a discussion of these two approaches for data assimilation on climatic timescales.

To adopt this approach for use in HadCM3, care has to be taken not to violate mass conservation in the model. A target pattern in terms of sea-level pressure could induce rather large mass fluxes. Therefore, it is undesirable to influence the sea level pressure field directly. While HadCM3 is a non-spectral model, where the winds in $u$ and $v$ direction are prognostic variables, these variables are transformed to vorticity and divergence. Changes in divergence would again introduce artificial mass fluxes into the model, but nudging vorticity avoids these artificial mass fluxes. A nudging pattern can therefore be determined by regressing the vorticity field onto the NAO index. 


\section{Results}

\subsection{Slowdown of the meridional overturning circulation}

In this section we analyze the climate response in the circum-North Atlantic region to a slowdown of the MOC by ca. $25 \%$. In both the ECBilt-Clio and HadCM3 models, the intensity of the MOC is defined as the maximum of the meridional overturning streamfunction in the North Atlantic below a depth of about $500 \mathrm{~m}$. For the ECBilt-Clio model, in addition to the 300 years simulation discussed here, several other simulations with a slightly different magnitude of the freshwater forcing and duration of the "hosing" were performed. All simulations show robust results in terms of MOC reduction, deep-water convection changes, and surface temperature response.

In the analysis of the results with the HadCM3 model, the means over the final 30 years of the hosing experiment are compared to the mean over the final 30 years of the control run, while for the ECBilt-Clio model we compare means over 100 years of the control and hosing simulation. Statistical significance in the difference of the means is tested using a standard Student $t$-test at a significance level of $90 \%$. For simplicity, discussion focuses on the winter and summer seasons only.

\subsubsection{ECBilt-Clio}

The hosing leads to a southward shift of the deep convection sites from off the southwestern Norwegian coast and south of Iceland to the region around $55^{\circ} \mathrm{N}-60^{\circ} \mathrm{N}$ northwest of the British Isles, together with a reduction in the depth of the convection layer. As expected for a weaker MOC, there is a decrease in the meridional heat transport in the Atlantic Ocean relative to control (Fig. 1a), with an absolute minimum of $0.12 \mathrm{PW}$ (annual average) at $33^{\circ} \mathrm{N}$ and largest relative changes in the band $60^{\circ} \mathrm{N}-70^{\circ} \mathrm{N}$ (Fig. 1b). As a consequence of the reduction in the meridional heat transport, negative SST anomalies, with a maximum change of $-4^{\circ} \mathrm{C}$ over the deep convection sites, are also apparent over this northerly region, together with a thickening and southward extension of the sea ice cover in the Norwegian Sea and south of Iceland and is broadly consistent with Ogilvie and Jonsson (2001) (not shown).

The change in surface air temperature for the winter (DJF) season (Fig. 2a) shows a center of maximum cooling of up to $2^{\circ} \mathrm{C}$ over the northern North Atlantic between Iceland and Norway. The cooling extends westward to Greenland, with a $0.75^{\circ} \mathrm{C}$ temperature decrease, and southeastward into the European continent, with temperatures of about $1.5-0.75^{\circ} \mathrm{C}$ colder over Scandinavia to about $0.2^{\circ} \mathrm{C}$ colder in southeastern Europe. Significant cooling of (a)
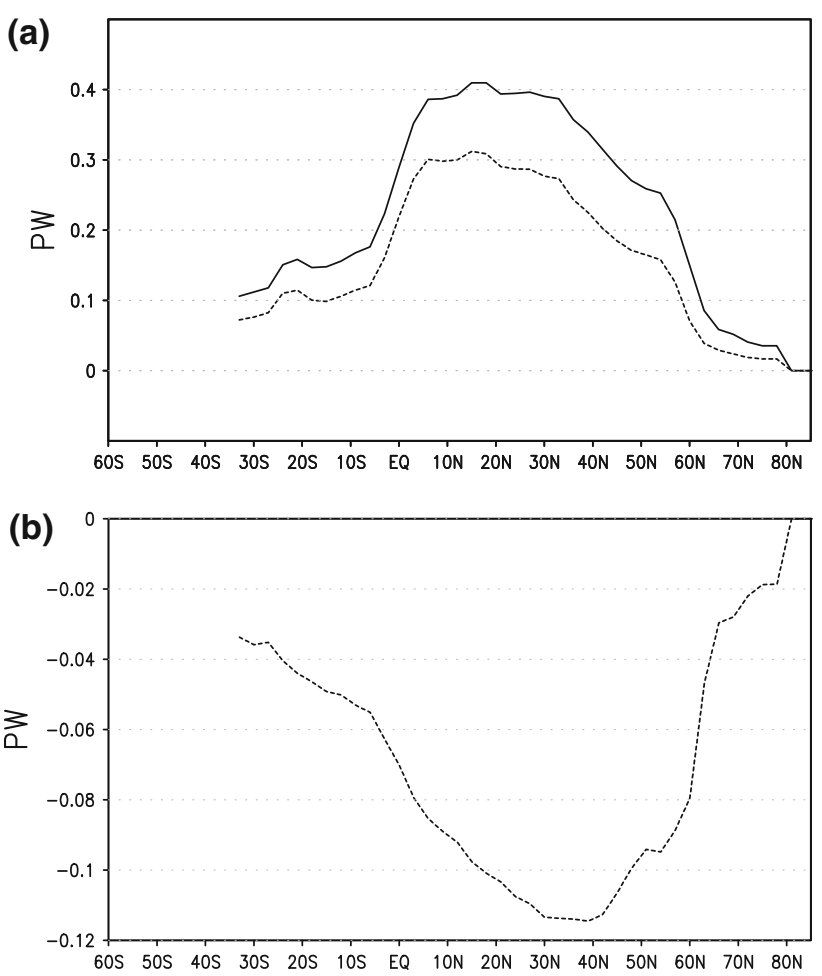

Fig. 1 Meridional heat transport for the Atlantic Ocean with the ECBilt-Clio model for (a) the control (solid line) and hosing run (dashed line), (b) anomalies in the hosing simulation relative to control

$0.2^{\circ} \mathrm{C}$ occurs over southern Asia, whereas a warming of $0.4^{\circ} \mathrm{C}$ is seen over northeastern North America. In the summer (JJA) season, temperatures are between 0.5 and $0.75^{\circ} \mathrm{C}$ colder over the British Isles and southern Scandinavia, and $0.4^{\circ} \mathrm{C}$ colder over southern Europe and the Mediterranean Sea (Fig. 2c). Colder air masses $\left(0.2^{\circ} \mathrm{C}\right)$ are also found over Russia and in the subtropical North Atlantic.

The response of the atmospheric circulation to the hosing is shown in Fig. 3. In winter, there is a distinct anomalous anticyclonic circulation over northern Scandinavia and Russia extending toward south of Iceland. This anomaly induces a weakening of the mean cyclonic circulation in the North Atlantic sector north of $40^{\circ} \mathrm{N}$. There is also an indication of a cyclonic circulation anomaly extending over central North America to the western subtropical North Atlantic. In summer, an anomalous anticyclonic circulation, with its center over the North Sea, extends over western Europe (Fig. 3c).

The change in winter atmospheric circulation during the hosing simulation suggests a decrease in the amplitude of the Icelandic Low pressure system (Fig. 3a) that could induce a change in the winter NAO variability. To check this, a NAO type index based on monthly December to March $800 \mathrm{hPa}$ streamfunction differences between the 
(a)

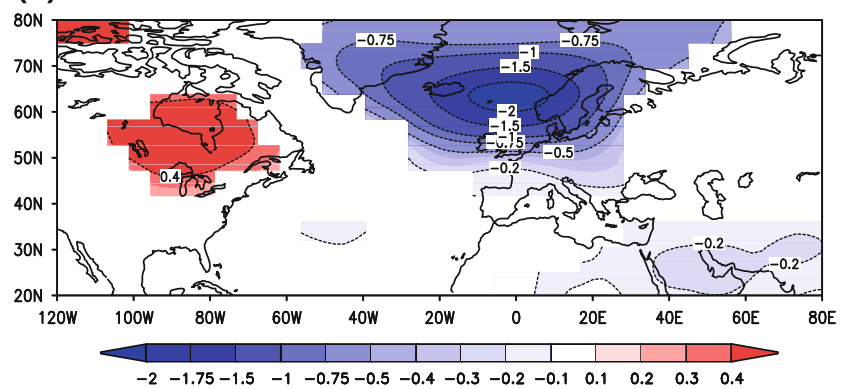

(c)

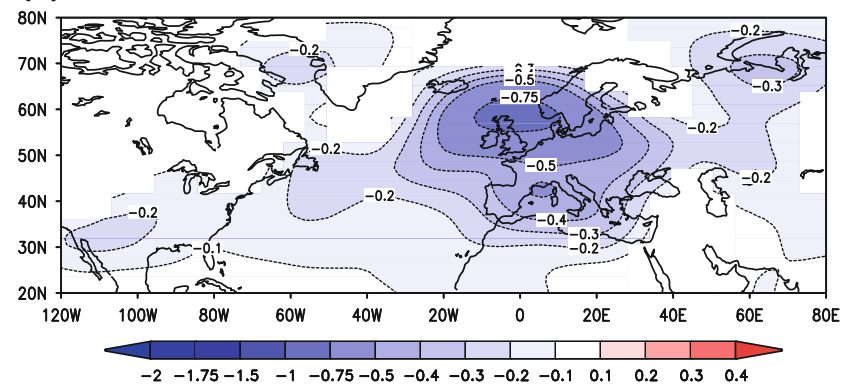

Fig. 2 Surface air temperatures changes due to a slowdown of the meridional overturning circulation by $25 \%$ for the ECBilt-Clio model (a, c) and for the HadCM3 model (b, d). Top panels show the

(a)

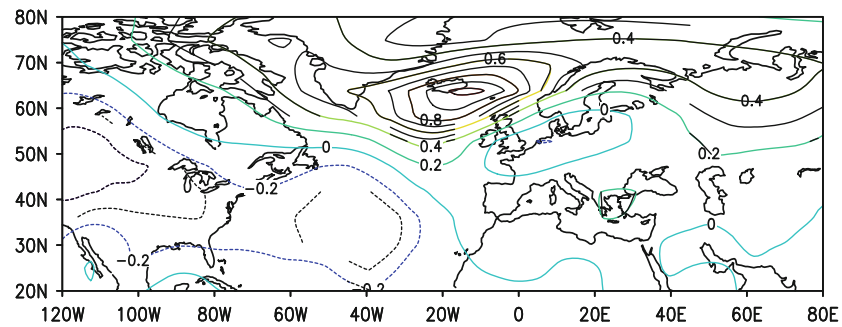

(c)

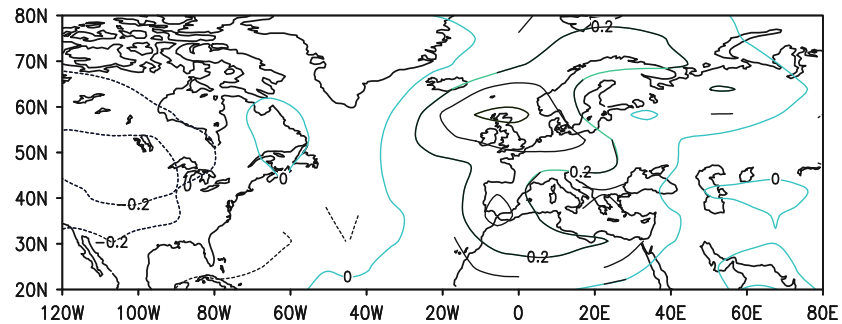

Fig. 3 Anomalies in $800 \mathrm{hPa}$ streamfunction for the ECBilt-Clio model $(\mathbf{a}, \mathbf{c})$ and in sea level pressure $(\mathrm{Pa})$ for the HadCM3 model (b, d), for the hosing experiments relative to control. Top (bottom)

Icelandic Low $\left(20^{\circ} \mathrm{W}, 65^{\circ} \mathrm{N}\right)$ and a region in the North Atlantic centered on $\left(20^{\circ} \mathrm{W}, 35^{\circ} \mathrm{S}\right)$, is constructed for both the control and hosing simulation. Note that both indexes are normalized by the mean and standard deviation of the control run. The probability distribution of NAO-like events shows somewhat of a bias towards the negative (b)

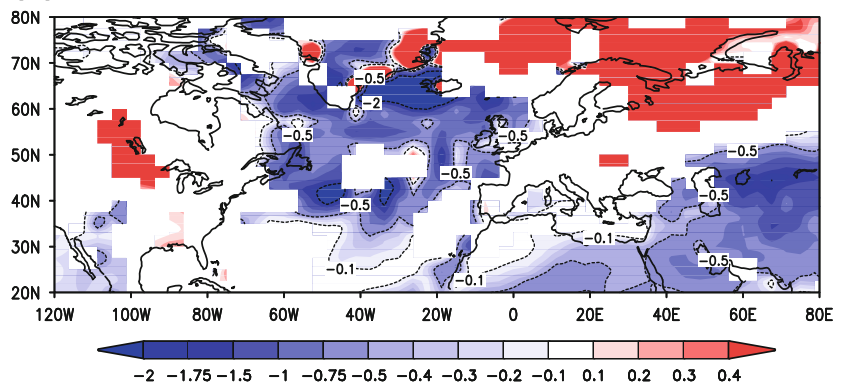

(d)

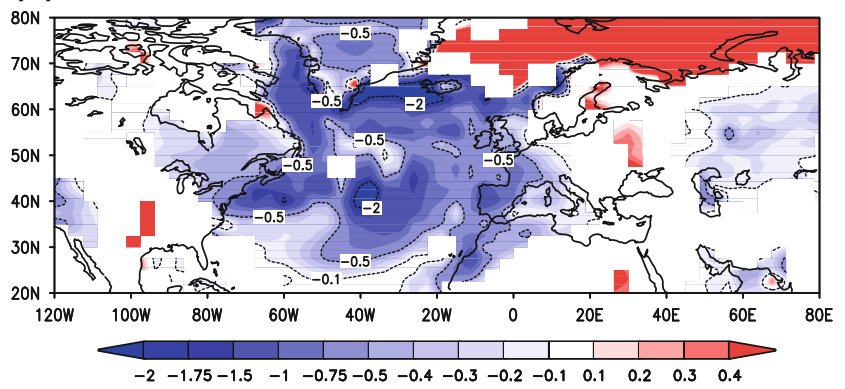

northern winter months (December, January, February; DJF), bottom panels show the summer months (June, July, August; JJA). Only values that are significant at the $90 \%$ level are shown

(b)

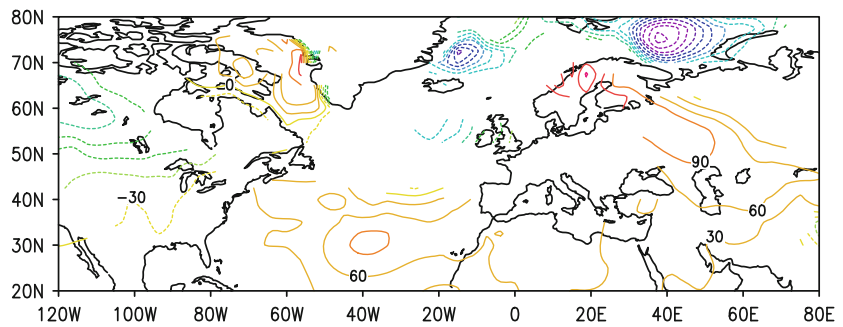

(d)

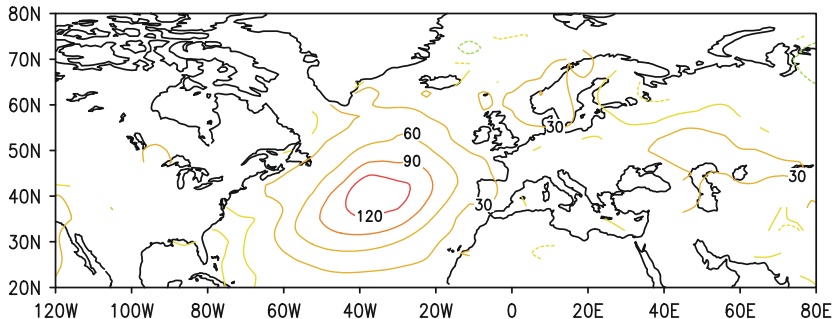

panels show anomalies in DJF (JJA). Changes that are significant at 90\% level are marked with black contours $(\mathbf{a}, \mathbf{c})$, in (b, d) only the significant differences are shown

phase of the NAO in the hosing simulation than in the control run, and the former also shows an increase in the frequency of extreme NAO events (Fig. 4). The difference between the two distributions is significant at the $90 \%$ significance level according to a Chi-squared test. A more active NAO negative phase is likely to be related to a 
decrease in the intensity of the westerly wind flow over the northeastern North Atlantic. Indeed, Fig. 5 shows a significant $(90 \%$ level) weakening in the zonally averaged westerly wind flow between $47^{\circ} \mathrm{N}$ and $55^{\circ} \mathrm{N}$, as well as in the polar easterlies, for the hosing relative to control, with no apparent change in the axis of the zonal jets.

The relationship between the NAO and the North Atlantic storm track position that transports heat and moisture to the European continent (Hurrel 1995) might suggest that the hosing would change intensity and position of storm tracks in the North Atlantic storminess. To investigate this, 4-hourly relative vorticity fields over the North Atlantic sector are analyzed. Following the suggestion of Hoskins and Hodges (2002), the planetary scales with total wavenumber less than or equal to five are removed from every field at each timestep in order to emphasize the synoptic scale variability. Figure 6 shows

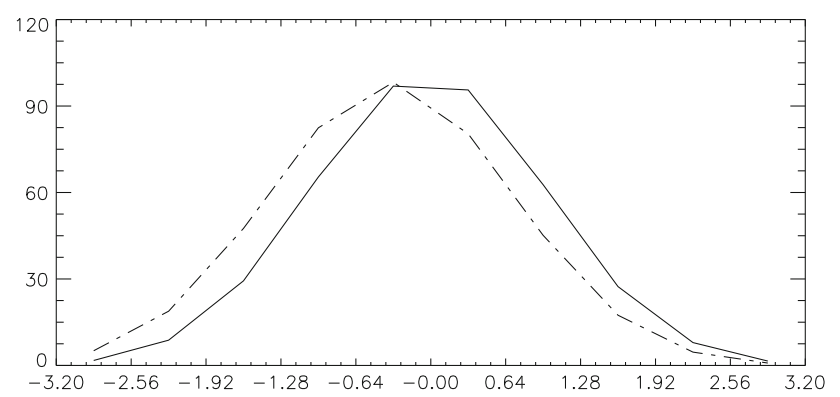

Fig. 4 Probability distribution of NAO-like events for the control (solid line) and hosing simulation (dashed line) within the ECBiltClio model. Both distributions were smoothed by fitting a Gaussian probability distribution function to the data and their difference is significant at the $90 \%$ significance level based on a Chi-square test

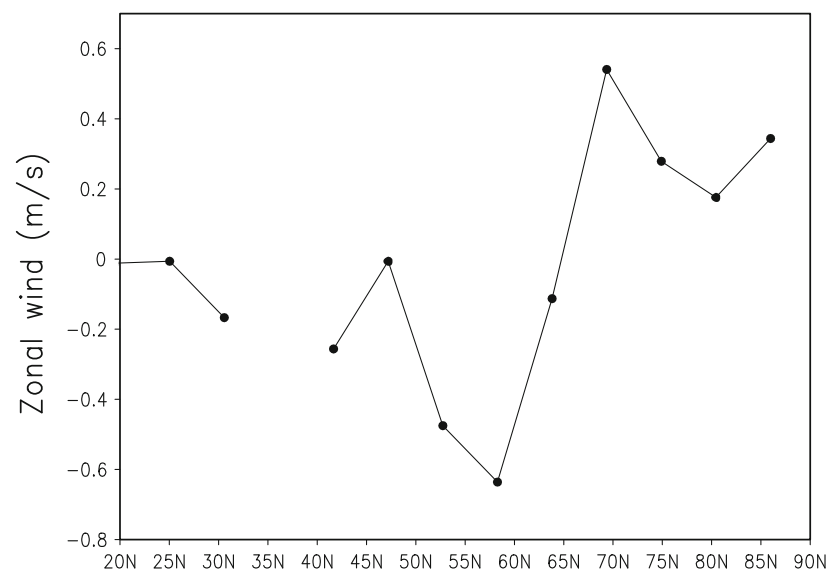

Fig. 5 Change in the zonally averaged $\left(60^{\circ} \mathrm{W}-20^{\circ} \mathrm{E}\right)$ zonal winds at the $800 \mathrm{hPa}$ level due to the slowdown of the meridional overturning circulation by 25 in the ECBilt-Clio model. Only significant changes at $90 \%$ significance level are shown the change in the total number of cyclones between the hosing simulation and the control run. Here a cyclone is defined as having a relative vorticity that is both lower than the mean minus the standard deviation for that gridbox and than the relative vorticity of the gridbox is lower than that of the neighbouring grid boxes. The standard deviation taken is that of the gridbox in the domain with the largest variability. An increase in cyclone activity is seen over the North Atlantic from off Newfoundland towards Scandinavia, with a maximum change northeast of the Faroe Islands, while to the north of Iceland a band of decreased cyclonic activity occurs. These changes seem to reflect a southward shift in the control storm track position, which would be indicative of the response of the North Atlantic storm track to a more frequent NAO negative phase during the hosing run (Fig. 4). Another region of higher cyclonic frequency occurs at the southern edge of the Baffin Bay. An increase in the sea-ice cover is observed over the latter region north of $70^{\circ} \mathrm{N}$ that could influence, by a larger air-sea temperature contrast, the baroclinicity of air masses flowing from the ice-edge into the open ocean, and thus cyclones growing at these latitudes.

\subsubsection{HadCM3}

The weakening of the MOC in the HadCM3 model induces a cooling in surface air and sea temperatures over most of the North Atlantic ocean (Fig. 2b). The region with maximum cooling (up to $3^{\circ} \mathrm{C}$ ) lies between Iceland and Greenland, while temperatures of about $1-2^{\circ} \mathrm{C}$ colder are found over the Labrador Sea and in the center of the subtropical gyre around $40^{\circ} \mathrm{N}$. Significant colder temperatures of $0.5-1{ }^{\circ} \mathrm{C}$ extend over southern Greenland and in the north Africa-southern Asia region; warmer temperatures of about $0.4^{\circ} \mathrm{C}$ are seen over central Canada.

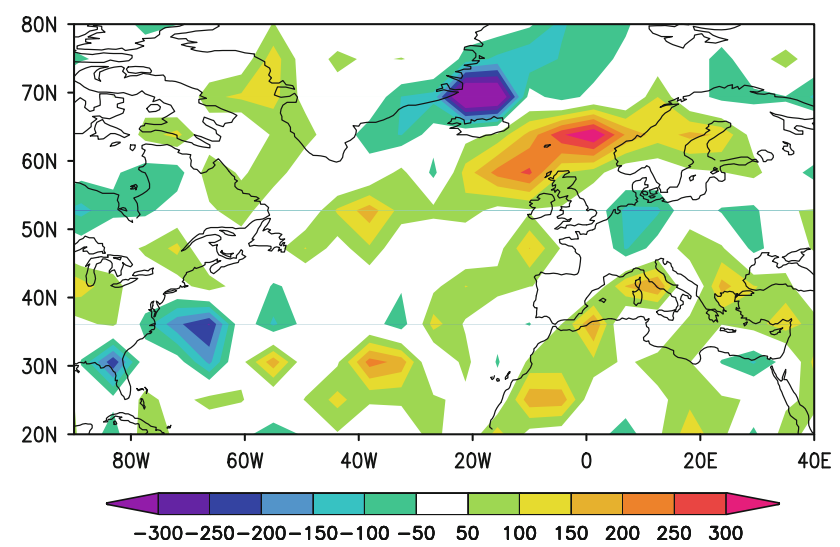

Fig. 6 Change in the number of cyclones over the North Atlantic sector (DJF season only) between the hosing experiment and the control run, aggregated over the length of the simulations. Values below 50 are not plotted 
As discussed in Stouffer et al. (2006), the HadCM3 model shows a warming of the high latitude North Atlantic caused by a northward shift of the deep-water convection and the associated increase in northward heat transport. On the other hand, much of the deep-water convection that takes place in the latitude belt between $50^{\circ} \mathrm{N}$ and $70^{\circ} \mathrm{N}$ is weakened by the freshwater hosing. In the summer season, the cooling extends further south in the North Atlantic and over the surrounding continental areas (Fig. 2d). In particular, temperatures are about $0.5-$ $1^{\circ} \mathrm{C}$ colder over southwestern Europe and $0.3^{\circ} \mathrm{C}$ colder over central Russia.

The response in the atmospheric circulation is shown as differences in SLP between the hosing and control run. In winter, significant increases in the SLP appear in the southeastern North Atlantic, the Labrador Sea, and over a region extending from Scandinavia towards Eastern Europe, whereas a significant anomalous cyclonic circulation is seen over North America, with a maximum in the northwest (Fig. 3b). Negative SLP anomalies present over the Greenland Sea and Arctic Ocean respond to the warmer SST there. In summer, an anomalous anticyclonic circulation centered around $40^{\circ} \mathrm{N}$ covers the subtropical North Atlantic, and positive SLP anomalies are also found over Scandinavia and Russia (Fig. 3d). The increase in the anticyclonic circulation over the subtropical North Atlantic seems to induce a strengthening of the westerly winds south of $50^{\circ} \mathrm{N}$ and a weakening north of it, both in winter and summer, although these changes are rather small (0.1$0.2 \mathrm{~m} / \mathrm{s}$ ) and not significant.

\subsection{Prescribed changes in the NAO index}

The NAO index gives an indication of the predominant atmospheric circulation in the North Atlantic area. If the NAO index is positive, i. e. lower than average pressure over Iceland, and higher than average pressure over the Azores, weather in Europe is dominated by circulation from the Atlantic. This results in mild and moist winter weather in western Europe. Conversely, a negative NAO index leads to a much reduced influence of North Atlantic weather, thereby leading to comparatively cool and dry winters.

Figure 7 shows a reconstruction of the NAO index for the December to March season based on the data of Luterbacher et al. (2004), for 1659-2001. To focus on the low frequency variability of the NAO, a low pass filter with a cut off period of 20 years was applied to the raw data. The low pass filtered signal indicates negative index values roughly coinciding with the 1675-1715 and the 1790-1820 periods, with the minimum values attained by the low-pass filtered signal in excess of -0.5 .

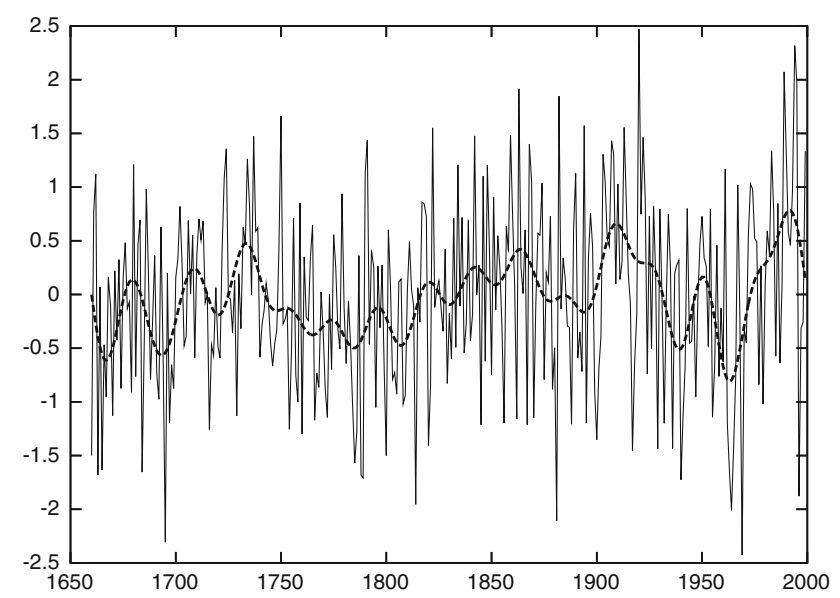

Fig. 7 Series of the NAO index reconstruction back to AD 1660, and its 20-year lowpass filtered version, expressed as an average of December to March monthly means

\subsubsection{ECBilt-Clio}

Figure 8a shows the target pattern in terms of streamfunction which is constructed using a regression analysis between winter NAO index values and reanalysis data. Figure $8 \mathrm{~b}$ shows the simulated DJF streamfunction, averaged over the length of the simulation. This figure demonstrates that the assimilation successfully reproduces the target pattern, giving a climate with, on average, a negative NAO index. The anomalous high-pressure center is located too far to the east, but the strength is correct. The anomalous low-pressure center is slightly too strong and located too far east. The pressure gradient north of $50^{\circ} \mathrm{N}$ in the model simulation is too strong, though the direction of the geostrophic flow is correct.

The anomalous winter temperatures (Fig. 11a) show the typical pattern associated with negative NAO-type circulations, with anomalous low temperatures over northern Europe and the southeastern USA, and anomalous high temperatures in the Mediterranean region and eastern North America.

In the data assimilation experiments, only winter circulation is modified. This could also affect summer conditions through an impact of the winter atmospheric circulation on components of the climate system with a large memory, like the upper ocean or the land surface. However, Fig. 12a shows that the impact on the summer temperatures in this experiment is modest.

\subsubsection{HadCM3}

Figure 9a shows the target pattern in terms of vorticity which is constructed using a regression analysis between winter NAO index values and reanalysis data. Figure $9 \mathrm{~b}$ shows the DJF-averaged vorticity, averaged over the length 

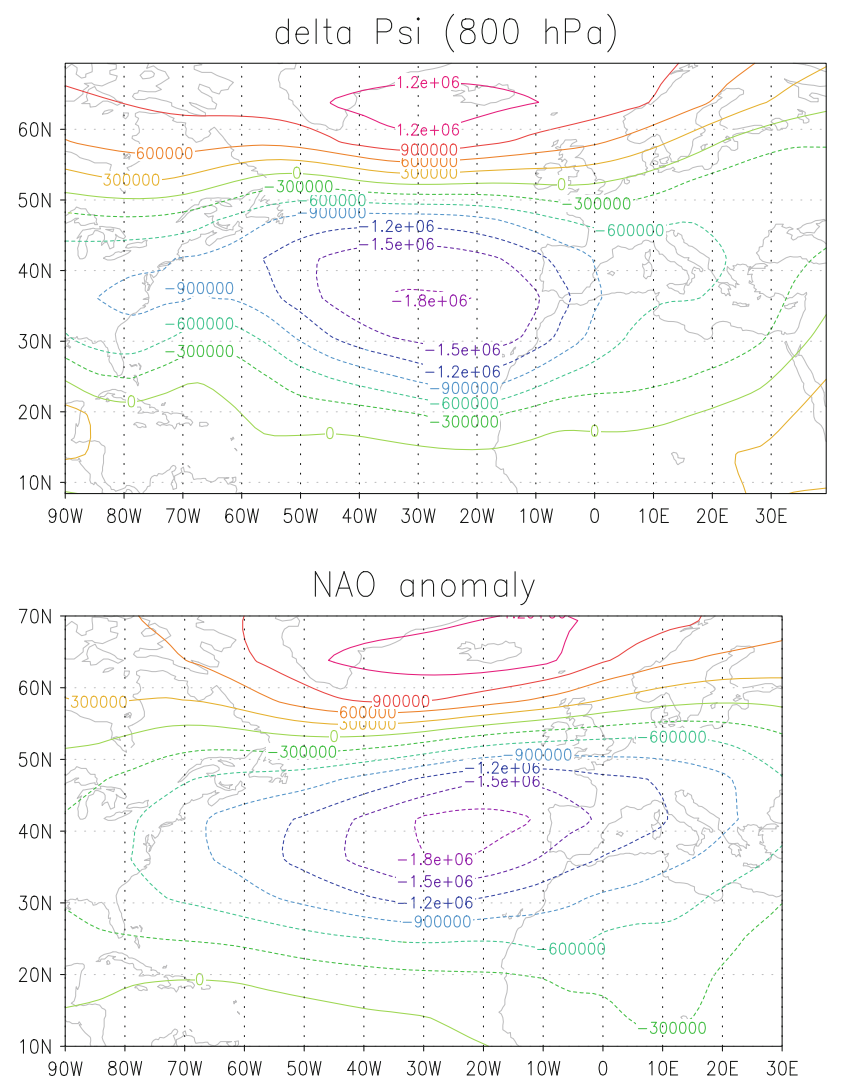

Fig. 8 The target pattern for the persistently negative NAO index experiment for the ECBilt-Clio model (upper panel). The lower panel shows the DJF-streamfunction, averaged over the length of the simulation, expressed as anomalies from climatology

of the simulation. This Figure demonstrates that the assimilation successfully reproduces the target pattern, giving a simulation of a climate with, on average, a negative NAO index. The main features of the target pattern are reproduced, with, in the North Atlantic sector, high vorticity in the subtropics and at high latitudes, and an area with low vorticity centered around $40^{\circ} \mathrm{N}$. The largest differences between the pattern nudging simulation and the target pattern are that the amplitude of the high vorticity region in the simulation over the northern North Atlantic is too low and that its focal point has shifted to southern Norway. The area with low vorticity around $40^{\circ} \mathrm{N}$ does not extent over the European continent in the simulation. The consequence of these mismatches is that the North Atlantic mid-latitude circulation has lost some of its zonality.

The imprint on sea-level pressure is shown in Fig. 10, which clearly shows the bimodal structure associated with the NAO. The anomalous low, which modifies the Azores high pressure center, is located in the mid-latitude North Atlantic and centered at $45^{\circ} \mathrm{N}$ and measures up to $500 \mathrm{hPa}$. The location of this anomalous low is too far west and north compared to observations. Further North, SLP increases by up to $200 \mathrm{hPa}$ over the Norwegian Sea.
Observations place this anomalous high over Iceland. In the simulation it is located between Iceland and Norway. This rotates the axis between the two centers of action clockwise, which results in the geostrophic flow having too great a meridional component compared to that observed. The negative SLP anomaly in the mid-latitude North Atlantic is centered at $45^{\circ} \mathrm{N}$, with a SLP decrease of up to $500 \mathrm{hPa}$.

Figure $11 \mathrm{~b}$ shows the difference in surface temperature between the model experiment, where the winter (DJF) NAO index has been forced toward a 30 year mean value of -0.5 , and the control run, where the NAO index is in a neutral mean state. Only the DJF NAO index was influenced, and in the HadCM3 simulation, temperature differences in MAM, JJA, and SON are very small, and not statistically significant. In DJF, on the other hand, some greater changes are apparent. West of the Atlantic, the negative NAO leads to cooling in the south-eastern part of the US, with lower SST in the North Atlantic up to $-2^{\circ} \mathrm{C}$, and a slight warming over Greenland. Over northeastern Europe and Russia temperatures are colder up to $1.5^{\circ} \mathrm{C}$, with hardly any changes apparent over Scandinavia. In Central and Eastern Asia, a strong warming of up to $2^{\circ} \mathrm{C}$ is also seen (not shown).

Figure $12 \mathrm{~b}$ shows that the impact on the summer temperatures on western Europe in this experiment cannot be distinguished from noise.

\section{Comparison to a reconstruction of Little Ice Age climate}

Reducing the MOC in the ECBilt-Clio and HadCM3 models with freshwater hosing leads to strong regional differences in the patterns of surface air temperatures anomalies over the European continent. These simulated climate anomalies can be compared to reconstructions of surface air temperatures during the LIA (Luterbacher et al. 2004). Here we select two particularly cold periods within the LIA, the 1675-1715 period, sometimes referred to as the 'Late Maunder Minimum', and the 1790-1820 period, sometimes referred to as the 'Dalton Minimum', and compute monthly mean temperature anomalies relative to 1971-2000. The temperature anomaly maps are shown in Fig. 13. Note that during the 1675-1715 and the 1790-1820 periods, reduced solar activity was coincidental with the occurrence of large major volcanic eruptions occurred (Briffa et al. 1998; Crowley 2000). The hosing experiment with the ECBilt-Clio model shows a pan-European cooling which is broadly consistent with the reconstructed temperatures for the two cold periods. In the model, the largest decrease is found just off-shore from southern Norway whereas the reconstructions have 
Fig. 9 The target pattern for the persistently negative NAO index experiment for the HadCM3 model in terms of vorticty based on a regression between NAO-index values and reanalysis data (upper panel). The lower panel shows the DIFvorticity pattern, averaged over the length of the simulation, anomalous from climatology
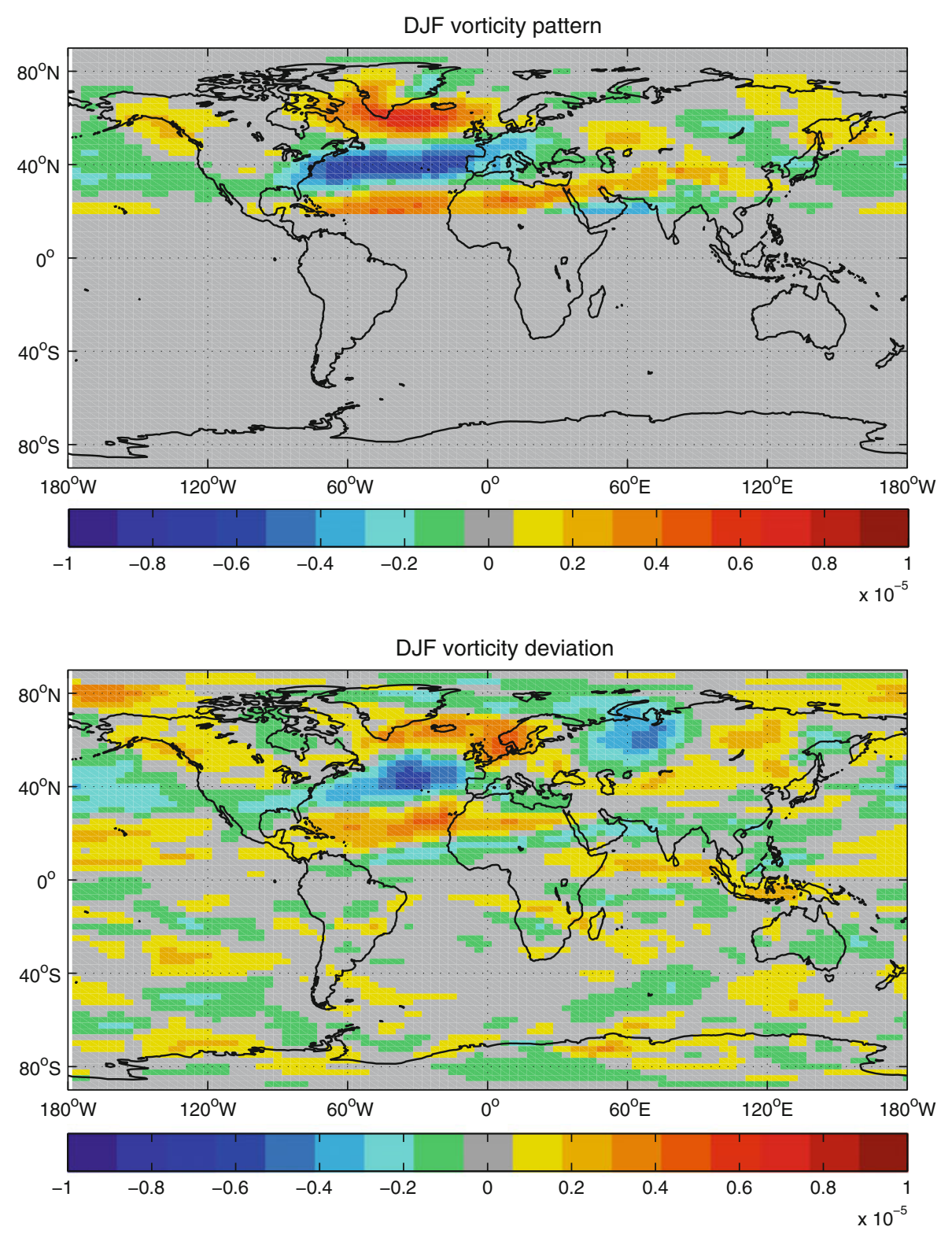

their greatest cooling in eastern Europe. However, the southward increase of winter temperatures over northwestern Europe and from the Baltic region towards the

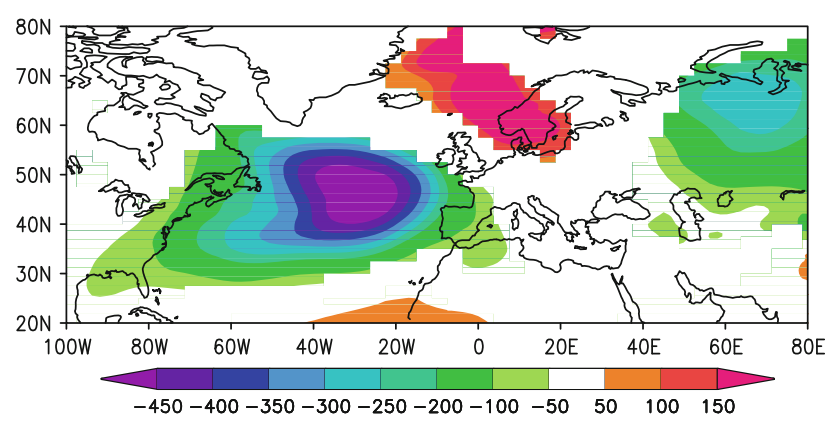

Fig. 10 Anomalous winter (DJF) sea level pressure (Pa) from the data-assimilated simulation from HadCM3. A clear bimodal structure associated with the NAO is present
Black Sea is reproduced (Fig. 2a). In the summer season, the reconstruction for the 1675-1715 period (Fig. 13c) shows a general cooling over Europe with a slight warming over the Balkan area. Reconstructed summer temperatures for the 1790-1820 period (Fig. 13d) show a clear contrast between either side of $10^{\circ} \mathrm{E}$ with colder temperatures to the west and warmer temperatures to its east, particularly over eastern Europe. These patterns of temperature reconstructions are not reproduced by the hosing experiments. The summer warming is absent in the ECBilt-Clio model and is not significant in the HadCM3 model (Fig. 2c,d), and the only consistency between models and reconstructions is the indication of relatively cool temperatures in (south-)western Europe.

The hosing experiment in both models leads to negative SST anomalies over the North Atlantic in both winter and 
(a)

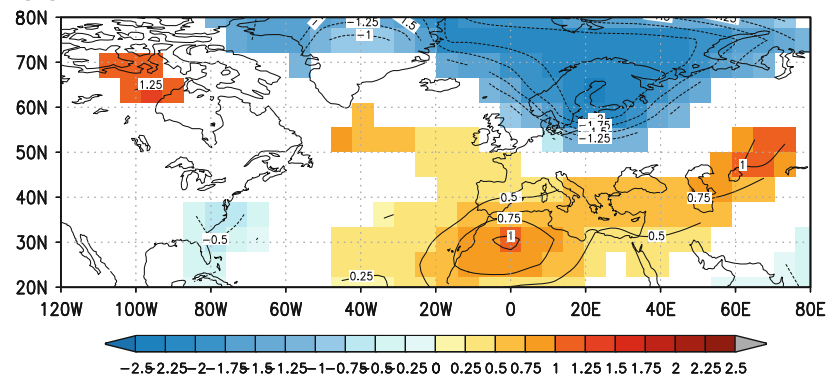

(b)

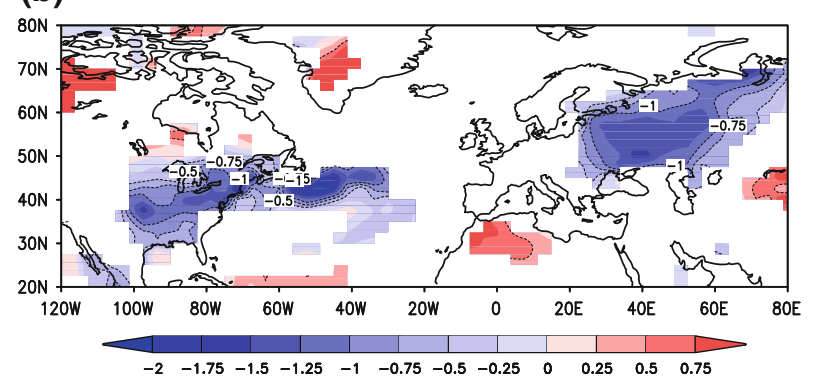

Fig. 11 Changes in winter (DJF) surface air temperature in a climate with negative NAO index, relative to control, for the ECBilt-Clio model (upper panel) and for the HadCM3 model (lower panel). Only significant values at a $90 \%$ significance level are shown

(a)

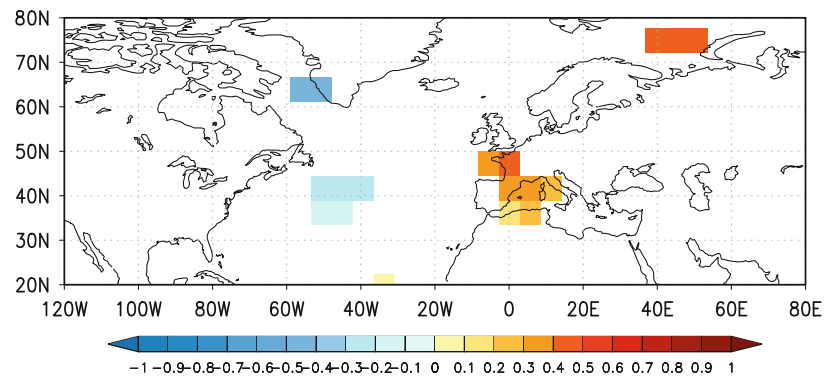

(b)

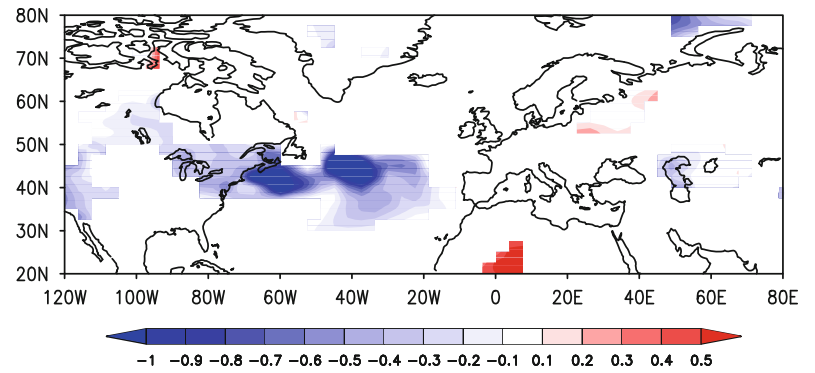

Fig. 12 Changes in summer (JJA) surface air temperature in the dataassimilated simulations of ECBilt-Clio (upper panel) and HadCM3 (lower panel). Only significant values at a $90 \%$ significance level are shown

summer which modifies the exchange of heat from the ocean to the atmosphere. This will affect sea level pressure as well. In this sense, the reduction of the overturning circulation will feedback on the character of the atmospheric response. The location of the winter atmospheric circulation anomaly in the ECBilt-Clio model (Fig. 2a) suggests that advection of cold air from high latitudes over Scandinavia is a main factor contributing to the decrease in surface air temperatures over northwestern Europe. In the HadCM3 simulation, the anomalous high pressure center over Russia-eastern Europe is likely to produce the lower temperatures seen to the east of the Caspian Sea. It is interesting to note that the winter atmospheric circulation anomaly that develops in the hosing experiment with the ECBilt-Clio model exhibit some similarity with the largescale SLP anomalies documented for several periods within the LIA (Luterbacher et al. 2002; van der Schrier and Barkmeijer 2005).

In both hosing experiments, changes in the North Atlantic wind stress curl associated with the winter circulation anomalies are not significant, implying that feedback mechanisms between the MOC reduction and the wind driven circulation via changes in the atmospheric circulation are not at work in the model experiments.

Assimilating a persistently negative winter season NAO circulation in the ECBilt-Clio model leads to a strong cooling over northwestern and northern Europe, while higher temperatures are observed over the Mediterranean region. This response is similar to what would be expected based on modern observations. The reconstruction of the winter temperature during the 1675-1715 and 1790-1820 periods shows severe cooling over the whole of Europe, whereas the simulation displays a north-south contrast.

The nudging experiment to impose a negative NAO index in the HadCM3 model in winter lead to decreased temperatures over eastern-Europe and northern Russia (Fig. 11b), a result that compares well with the temperature reconstructions for the 1790-1820 period (Fig. 13b). However, the simulation fails to show cooling over western Europe, a rather surprising result considering the link between the NAO and the LIA invoked in the literature (Shindell et al. 2001; Luterbacher et al. 2002). A cause for this could be related to the reorientation of the NAO pattern in this simulation, which results in advection of air from southeastern to western Europe, rather than advection of the colder continental air masses. On the other hand, the model shows negative SST anomalies over the western North Atlantic between $40^{\circ} \mathrm{N}$ and $50^{\circ} \mathrm{N}$, which are consistent with a negative NAO index (Hurrel 1995).

The persistence of the change in temperatures into the summer season is, however, weak. In summer, when no data assimilation is performed, the simulation with the ECBilt-Clio model shows no significant cooling over western Europe, with only a weak warming over the Iberian Peninsula. The summer temperature change in the HadCM3 model is not statistically significant. This is in 

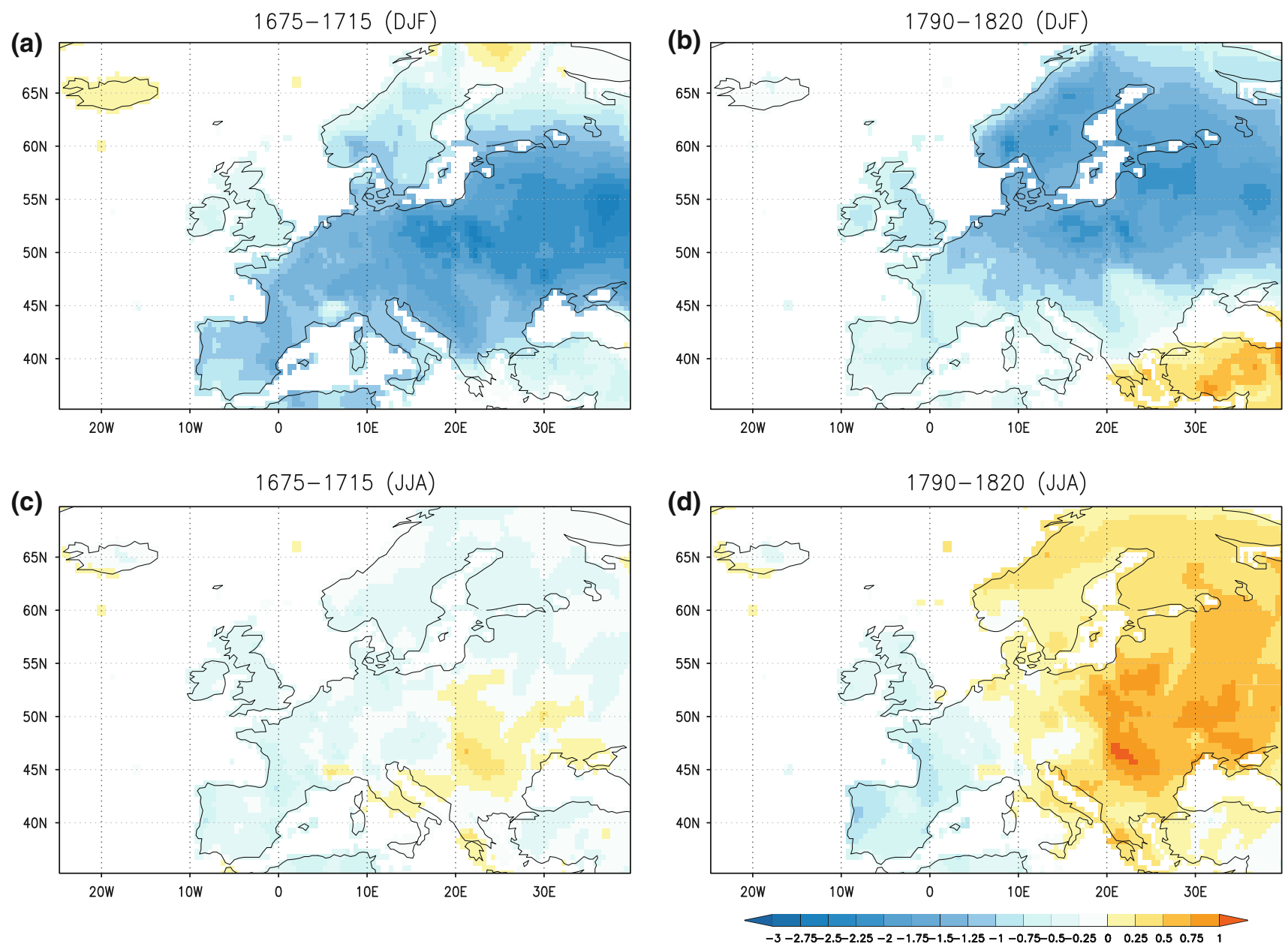

Fig. 13 Differences in reconstructed surface air temperature for the period 1675-1715 AD (left panels) and the 1790-1820 AD (right panels) with respect to 1971-2000. Upper panels denote anomalous

sharp contrast with the reconstruction of summer temperatures for the 1675-1715 and 1790-1820 periods, where a distinct cooling in western Europe is apparent, along with a warming in eastern Europe during the latter period.

\section{Discussion and conclusions}

In an effort to distinguish between a persistently negative NAO-type circulation and a reduction in the Atlantic MOC as the primary drivers of the cooling observed in the European LIA, two sets of experiments are performed. One in which a climate is simulated with a constant and negative NAO-index and one with a reduced overturning. Each set of experiment is done with an intermediate-complexity and a full complexity GCM. A comparison between the modelled temperatures and a reconstruction of LIA temperatures is at the basis of distinguishing between the two hypothesis.

winter (DJF) tempatures, lower panels denote anomalous summer (JJA) tempatures. Temperature reconstruction is from Luterbacher et al. (2004)

This study shows that the hypothesis that LIA cooling is related to a circulation in the North Atlantic sector with a persistently negative NAO-index is unlikely to be valid. The model results do not convincingly reproduce the overall winter cooling see in Europe during the LIA period and persistence of this cooling into the summer season is weak.

The hosing experiments do not clearly support the hypothesis that a reduction in the MOC is the primary driver of LIA climate change. The hosing experiment with the ECBilt-Clio model shows a cooling which has similarities with the reconstructed temperatures for the LIA climate, but the largest cooling is off-shore. The reconstructions have their greatest cooling in eastern Europe which hints at a change in atmospheric circulation as an explanation for this pattern. Moreover, these experiments shows no similarity with the character of the reconstructed summer temperature signal either, which may have persisted from the preceeding winter, due to the conservative nature of surface ocean temperatures or soil moisture. 
However, the hosing explanation cannot be entirely discounted either. The experiments indicate that the feedback of changing SSTs due to the reduction in the overturning, lead to significant changes in atmospheric circulation with subsequent modification of the direct effect of changing ocean temperatures. The combination of the direct effect of cool oceanic surface temperatures and a modified atmospheric circulation remains a possible explanation.

A reconstruction of the winter atmospheric circulation for the 1790-1820 period clearly shows the anticyclonic anomaly in the northern North Atlantic (Lamb and Johnson 1959; van der Schrier and Barkmeijer 2005), which is in very good agreement with the anticyclonic circulation anomaly simulated here (Fig. 3a). However, in the present simulation the low pressure anomaly over the western North Atlantic and eastern US seaboard appears to be weaker and it does not correspond to the other aspects seen such as the anomalous cyclonic circulation over Central Europe. Nevertheless, the occurrence of high SLP anomalies with centers over northern Europe/Scandinavia is a recurrent feature of the atmospheric circulation in extreme cold periods of the LIA that has also been connected to the NAO variability (Luterbacher et al. 2002). A main conclusion from the present experiments with the ECBilt-Clio model is that the climatic response to a reduction in the strength of the MOC will directly impact temperatures in the North Atlantic sector, but it will also feedback on the atmospheric circulation. The latter will extort an additional modifying influence on European climate and its effect will be comparable, if not larger, than the direct effect of the MOC reduction.

In particular, Bjerknes (1965) argued that during the LIA, its climate was strongly influenced by the occurrence of anomalous high pressure centered in the North Atlantic, south of Iceland and anomalous low pressure off the eastern seaboard of the US.

In earlier experiments (van der Schrier and Barkmeijer 2005), the reconstructed winter atmospheric circulation for the 1790-1820 period was assimilated in the ECBilt-Clio model and that resulted in a strong resemblance of both winter and summer simulated temperatures with reconstructed temperatures. In the light of this earlier result, the present study suggests that the explanation of the coldness of this period hinges on the pattern of atmospheric circulation change, but not specifically a change in the NAO.

\footnotetext{
Acknowledgments NCEP Reanalysis data were provided by the NOAA-CIRES Climate Diagnostics Center, Boulder, Colorado, USA, from their Web site at http://www.cdc.noaa.go. VP and GvdS were funded by the Netherlands Organisation for Scientific Research (ALW - NWO) and TK, TJO and KRB acknowledge support from the UK Natural Environmental Research Council (NERC). Funding for all authors is through the joint UK-NL RAPID Climate Change programme (To what extent was the Little Ice Age a result of a change in the THC? NE/C509607/1).
}

Open Access This article is distributed under the terms of the Creative Commons Attribution Noncommercial License which permits any noncommercial use, distribution, and reproduction in any medium, provided the original author(s) and source are credited.

\section{Appendix: Data assimilation techniques}

Data assimilation (referred to subsequently as DA hereafter) techniques are intended to force a model state toward some prescribed or observed field. This is done in operational weather forecasting by constructing an initial condition which leads after a short integration to the observed field. For every new forecast, a new initial condition needs to be computed. This technique requires very detailed knowledge of the atmospheric state, till at the level of the smallest spatially resolved scales and at a temporal scale of days. In paleoclimatology, this precise knowledge of the past atmospheric state is lacking as one typically has proxy or documentary data from only a few locations, often reflecting climate signals that are integrated over weeks or months (or longer). This renders the traditional DA techniques unsuitable for application to paleoclimatologic situations.

Both data-assimilation methods used in this study have a similar two-phase set-up. The first step is the upscaling step. The available paleodata are integrated in an upscaling model to relate the available data to one (or more), largescale anomalous circulation patterns. These patterns, the target patterns, are used as input to the assimilation procedure. Generally, the target pattern is a slowly varying (or constant) pattern and represents a modification to the largescale general circulation.

The second phase in the assimilation procedure is to perturb the tendencies of the GCM to reproduce, in a timeaveraged sense, the target pattern. Critical in this approach is not to reduce the synoptic scale variability, for which no information exists in the target pattern (or in paleoclimatic records), but to change the synoptic scale variability in a way that is dynamically consistent with the general circulation.

The two assimilation techniques differ in the way the tendency perturbations are calculated. Here we take streamfunction as an example. The model atmospheric circulation $\psi$ is decomposed in a climatology $\psi_{\text {clim }}$ and a set of orthogonal modes as follows:

$\psi(x, t)=\psi_{\text {clim }}+\alpha_{1} \psi_{\text {target }}+\sum_{i=2}^{\infty} \alpha_{i} \psi_{i}$

The target pattern $\psi_{\text {target }}$ is the first of the orthogonal modes. The internal variability orthogonal to the target pattern is captured in the remaining modes $\psi_{i}$. 


\section{Assimilation using forcing singular vectors}

Tendency perturbations can be calculated using forcing singular vectors (Barkmeijer et al. 2003) which require the use of a so-called adjoint model (Lacarra and Talagrand 1988). A detailed description of forcing singular vectors and the new DA technique is give by Barkmeijer et al. (2003) and van der Schrier and Barkmeijer (2005). Here we present a brief description only.

We are interested in tendency perturbations, $\mathbf{f}$, that will produce, after some integration time (the optimization time) a deflection of the model atmospheric state in the direction of the target pattern. If the tendency perturbations are sufficiently small, the evolution of deviations of the model atmospheric state which results from tendency perturbations can be computed by a linearization of the GCM along a (time-dependent) solution of this GCM. In this DA technique, the optimal three-dimensional spatial pattern of the tendency perturbations is determined subject to the requirement that the projection of the model's streamfunction onto the target pattern is one, at the endpoint of the optimization time. The tendency perturbations are held fixed in time during the optimization time.

The calculations which lead to tendency perturbations are based on a minimization of a cost function. In this cost function an operator is introduced which is a projection operator onto the $800 \mathrm{hPa}$ level over the extratropical North Atlantic sector. The atmospheric state outside the North Atlantic sector (north of the subtropics) and on the levels higher than $800 \mathrm{hPa}$ is not considered in the cost function. An efficient way to minimize the cost function is to use the adjoint of the linearization of the GCM.

After the evaluation of the tendency perturbations in the framework of the linearized system, the tendency perturbations are applied to the nonlinear coupled GCM. The forcing singular vectors have amplitudes which are typically less than 1 of the total tendencies which implies that the linearity assumption holds. The tendencies modify the model atmospheric circulation in the direction of the target pattern only, generally a large-scale pattern, leaving smaller scale variability, like synoptic scale features, to evolve freely.

A linearization of the atmospheric part (ECBilt) dynamic core of the climate model and its adjoint exist, are used here in the evaluation of the forcing perturbation $\mathbf{f}$. Atmospheric physics is not included in the computation of f; an accurate approximation if the optimization time is sufficiently small. In the current application, this is $96 \mathrm{~h}$, which means that every $96 \mathrm{~h}$ the tendency perturbations are updated.

\section{References}

Barkmeijer J, Iversen T, Palmer TN (2003) Forcing singular vectors and other sensitive model structures. Q J R Meteorol Soc 129:2401-2423

Bianchi GG, McCave IN (1999) Holocene periodicity in North Atlantic climate and deep-ocean flow south of Iceland. Nature 397:515-517

Bjerknes J (1965) Atmosphere-ocean interaction during the "Little Ice Age". In: WMO-IUGG symposium on research and development aspects of longe-range forecasting WMO-No. 162. TP. 79, pp 77-88, Technical Note No. 66

Boessenkool KP, Hall IR, Elderfield H, Yashayaev I (2007) North atlantic climate and deep-ocean flow speed changes during the last 230 years. Geophys Res Lett 34:285. doi:10.1029/ 2007GL030

Bond G, Showers W, Cheseby M, Lotti R, Almasi P, deMenocal P, Priore P, Cullen H, Hajdas I, Bonani G (1997) A pervasive millennial-scale cycle in the north atlantic holocene and glacial climates. Science 278:1257-1266

Bradley RS, Jones P (1993) Little ice age' summer temperature variations: their nature and relevance to recent global warming trends. The Holocene 3(4):367-376

Briffa KR, Jones PD, Schweingruber FH, Osborn TJ (1998) Influence of volcanic eruptions on Northern Hemisphere summer temperatures over the past 600 years. Nature 393:450-455

Broecker W (2000) Was a change in the thermohaline circulation responsible for the Little Ice Age? Proc Nat Acad Sci 97:13391342

Cook ER, D'Arrigo D, Mann ME (2002) A well-verified, multiproxy reconstruction of the winter North Atlantic Oscillation index since a.d. 1400. J Clim 15:1754-1744

Crowley TJ (2000) Causes of climate change over the past 1000 years. Science 29:270-277

Dickson RR, Lazier J, Meincke J, Rhines P, Swift J (1996) Long term coordinated changes in the convective activity of the north atlantic. Prog Oceanogr 38:241-295

Goosse H, Fichefet T (1999) Imporance of ice-ocean interactions for the global ocean circulation: a model study. J Geophys Res 104:23337-23355

Goosse H, Deleersnijder E, Fichefet T, England MH (1999) Sensitivity of a global ocean-sea ice model to the parametrization of vertical mixing. J Geophys Res 104: 13681-13695

Gordon C, Cooper C, Senior CA, Banks H, Gregory JM, Johns TC, Mitchell JFB, Wood RA (2000) The simulation of SST, sea ice extents and ocean heat transports in a version of the Hadley Centre coupled model without flux adjustments. Clim Dyn $16: 147-168$

Grove J (1988) The Little Ice Age. Methuen \& Co, London

Hoskins B, Hodges K (2002) New perspectives on the northern hemisphere winter storm tracks. J Atmos Sci 59:1041-1061

Hurrel JW (1995) Decadal trends in the North Atlantic Oscillation: regional temperatures and precipitation. Science 269:676-679

Jansen E, Overpeck J, Briffa KR, Duplessy J-C, Joos F, MassonDelmotte V, Olago D, Otto-Bliesner B, Peltier WR, Rahmstorf S, Ramesh R, Raynaud D, Rind D, Solomina O, Villalba R, Zhang D (2007) Paleoclimate. In : Solomon S, Qin D, Manning M, Chen Z, Marquis M, Averyt KB, Tignor M, Miller HL (eds) Climate change 2007: the physical science basis. Contribution of working group I to the fourth assessment report of the intergovernmental panel on climate change. Cambridge University Press, Cambridge, pp 433-498

Jones JM, Widmann M (2003) Reconstructing large-scale variability from palaeoclimatic evidence by means of Data Assimilation 
Through Upscaling and Nudging (DATUN). In: Fischer H, Kumke T, Lohmann G, Flöser G, Miller H, von Storch H, Negendank JFW (eds) The KIHZ project: towards a synthesis of Holocene proxy data and climate models. Springer, Berlin

Keigwin LD (1996) The Little Ice Age and Medieval Warm Period in the Sargasso Sea. Science 274:1504-1508

Keigwin LD, Boyle EA (2000) Detecting Holocene changes in thermohaline circulation. Proc Nat Acad Sci 97:1343-1346

Keigwin LD, Pickart RS (1999) Slope water current over the Laurentian Fan on interannual to millennial time scales. Science 286:520-523

Kleinen T, Osborn T, Briffa K (2007) Assimilating NAO index states into GCMs: the case of the "Little Ice Age". J Clim (submitted)

Lacarra J, Talagrand O (1988) Short range evolution of small perturbations in a barotropic model. Tellus A 40:81-95

Lamb HH, Johnson AI (1959) Climatic variation and observed changes in the general circulation. Part I and Part II. Geogr Ann 41:94-134

Luterbacher J, Rickli R, Xoplaki E, Tinguely C, Beck C, Pfister C, Wanner H (2001) The late Maunder Minimum (1675-1715) - a key period for studying decadal scale climatic change in Europe. Clim Change 49:441-462

Luterbacher J, Xoplaki E, Dietrich D, Rickli R, Jacobeit J, Beck C, Gyalistras D, Schmutz C, Wanner H (2002) Reconstruction of Sea Level Pressure fields over the Eastern North Atlantic and Europe back to 1500 . Clim Dyn 18:545-561

Luterbacher J, Dietrich D, Xoplak E, Grosjean M, Wanner H (2004) European seasonal and annual temperature variability, trends and extremes since 1500. Science 303:1499-1503

Ogilvie AEJ, Jonsson T (2001) Little Ice Age research: a perspective from iceland. Clim Change 48:9-52

Opsteegh JD, Haarsma RJ, Selten FM, Kattenberg A (1998) Ecbilt: a dynamic alternative to mixed boundary conditions in ocean models. Tellus A 50:348-367

Pardaens AK, Banks HT, Gregory JM, Rowntree PR (2003) Freshwater transports in hadcm3. Clim Dyn 21:177-195

Pope VD, Gallani ML, Rowntree PR, Stratton RA (2000) The impact of new physical parametrizations in the Hadley Centre climate model: Hadam3. Clim Dyn 16:123-146

Rodrigo FS, Pozo-Vazquez D, Esteban-Parra MJ, Castro-Diez Y (2001) A reconstruction of the winter North Atlantic Oscillation index back to a.d. 1501 using documentary data in southern spain. J Geophys Res 106:14805-14818
Rodwell MJ, Rodwell DP, Folland CK (1999) Oceanic forcing of the wintertime North Atlantic Oscillation and European climate. Nature 398:320-323

Sedlácek J, Mysak LA (2009) Sensitivity of sea ice to wind-stress and radiative forcing since 1500: a model study of the Little Ice Age and beyond. Clim Dyn 32:817:831. doi:10.1007/s00382-0080406-6

Shindell DT, Schmidt GA, Mann MA, Rind D, Wapple A (2001) Solar forcing of regional climate change during the Maunder Minimum. Clim Dyn 294:2149-2152

Stouffer RJ, Dixon KW, Spelman MJ, Hurlin W, Yin J, Gregory JM, Weaver AJ, Eby M, Flato GM, Robitaille DY, Hasumi H, Oka A, $\mathrm{Hu}$ A, Jungclaus JH, Kamenkovich IV, Levermann A, Nawrath S, Montoya M, Murakami S, Peltier WR, Vettoretti G, Sokolov A, Weber SL, (2006) Investigating the causes of the response of the Thermohaline Circulation to past and future climate changes. J Clim 19:1365-1387

Trouet V, Esper J, Graham NE, Baker A, Scourse JD, Frank D (2009) Persistent positive North Atlantic Oscillation Mode Dominated the Medieval Climate Anomaly. Science 324:78-80. doi: 10.1126/science. 1166349

van der Schrier G, Barkmeijer J (2005) Bjerknes hypothesis on the coldness during ad 1790-1820 revisited. Clim Dyn 25:537-553

van der Schrier G, Barkmeijer J (2007) North American 1818-1824 drought and 1825-1840 pluvial and their possible relation to the atmospheric circulation. J Geophys Res 112:D13 102. doi: 10.1029/2007JD008429

van der Schrier G, Drijfhout SS, Hazeleger W, Noulin L (2007) Increasing the Atlantic subtropical jet cools the circum-North Atlantic. Meteorlogische Zeitschrift 16:675-684

von Storch H, Cubach U, González-Rouco FJ, Jones MJ, Voss R, Widmann M, Zorita E (2000) Combining paleoclimatic evidence and $\mathrm{gcms}$ by means of data assimilation through upscaling and nudging (Datun). In: Proceedings of 11th symposium on global change studies, pp 1-4, AMS

Weber SL, Drijfhout SS, Abe-Ouchi A, Crucifix M, Eby M, Ganapolski A, Murakami S, Otto-Bliesner B, Peltier W (2007) The modern and glacial overturning circulation in the atlantic ocean in pmip coupled model simulations. Clim Past 3:51-64

Widmann M, Goosse H, van der Schrier G, Schnur R, Barkmeijer J (2009) Using data assimilation to study extratropical Northern Hemisphere climate over the last millennium. Clim Past Discuss 5:2115-2156. http://www.clim-past-discuss.net/5/2115/2009/ 